\title{
Establishment of Mental Health Maintenance and Quality Improvement Mode of Employees in Driving Schools in Jilin Province
}

\author{
Xiaoying Qi \\ Jilin Agricultural Science and Technology University, Jilin, 132101, China \\ email:350348580@qq.com
}

Keywords: Driving School Enterprises, Mental Health, Management, HSE

\begin{abstract}
This paper analyzes the implementation status of mental health maintenance and quality improvement of driving school staff in Jilin Province, expounds the importance and necessity of establishing the mental health management mode of driving school staff in Jilin Province, and puts forward suggestions for strengthening the construction of mental health management mode.
\end{abstract}

\section{Introduction}

Driving school work has the characteristics of high degree of danger and high labor intensity. In addition, factors such as long working hours in cars and closed working environment make it easy for employees to produce cervical diseases of the body, poor mental work mood and many other problems. The author used the Symptom Checklist (SCL-90) to test 300 employees of several driving school Enterprises in Jilin Province[1]The results show that the number of somatization, anxiety, coercion and positive items of this type of enterprise employees is significantly higher than that of other units in the country. The interpersonal relationship factors are significantly lower than the national norm, and the difference is statistically significant .It is suggested that employees of this type of enterprise are vulnerable to physical and mental health and are also prone to emotional reactions such as emotional disorders. Therefore, it is imperative to establish a mental health management model in this type of enterprise.

\subsection{Status of Implementation of Mental Health Maintenance and Quality Improvement Models at Home and Abroad}

The Employee Assistance Program (EAP) is a mature mental training and grooming management model. Although each company's EAP project will vary according to different stages and regions, its contents include: professionals providing diagnostic training, counseling and guidance for employees, helping family members of employees, professional mental health, layoffs psychological crisis, career development, healthy lifestyle, stress management, diet issues, etc. This management model is widely adopted in foreign countries to improve the overall efficiency of the enterprise and achieve the established goals of the enterprise. More than $90 \%$ of the world's top 500 companies have established employee mental health plans. In the United States and other countries, nearly one-quarter of employees enjoy employee mental health program services. Some governments have become more active in their mental health plans. They believe that employee mental health programs not only bring benefits to the company, but also benefit the society. Some governments have also strengthened their supervision of employee mental health programs in legislation, so that employees' mental health plans have received more attention, respect, regulation and dissemination [2].

Most domestic enterprises tend to pay more attention to the health status of employees, and regularly give physical examination, active prevention and treatment, but mental health problems have not received corresponding attention. Reflected in the work, some employees "have more understanding" than before, "be able to talk about conditions", and some people are irritable and have greater work pressure. Most enterprise security management is replaced by administrative punishment and economic punishment. Managers do not pay attention to the psychological problems of employees, which seriously affects the 
mental health of employees.

A related report shows: in 2018, about $61 \%$ of Chinese professionals feel that work pressure is high. However, a survey report of the occupational mental health management of Chinese corporate employees on "What kind of actions managers take on mental health services" shows that about $27 \%$ of companies will provide training, and about $26 \%$ of companies still have No action, $23 \%$ of companies have increased their propaganda in the company's internal publications, about $17 \%$ of the companies will provide thematic activities, and about $8 \%$ of the companies will purchase employee psychological assistance/consultation projects. It can be seen that Chinese companies have taken some measures in terms of employees' mental health management and assistance, but they are all in their infancy.

\subsection{The Importance and Necessity of Mental Health Maintenance and Quality Improvement in Driving Schools}

Mental health management maintenance and quality improvement is the guarantee for training safe drivers (teaching).

As a company that trains drivers, driving school often have long working hours in cars and the environment is relatively fixed and closed. The HSE management system requires attention to safety and environmental protection as well as the health of employees. Health refers not only to the body but also to mental health. Whether it is the company's top management or ordinary employees, they are faced with internal and external pressures from work, study, and family. Only by paying attention to mental health and improving the employee happiness index can safety work be more secure. If the mentality is unhealthy, the mentality is not good, and even the emotional response to the student's guidance work, the safety of the work cannot be guaranteed. [3]And it will affect the driver or more people.

\subsubsection{Mental Health Maintenance and Quality Improvement are the Basis for Effectively Improving the Management Level of Driving School Enterprises}

A study in the United States found that when occupational requirements and employee tolerance and resources do not match, employees will have three harmful reactions. In the fierce competition of the industry, the emotional and psychological problems caused by the personality traits and pressure of employees will be manifested, which will not only affect the physical and mental health of the parties, but also affect the mental health of family members and colleagues, resulting in economic losses of enterprises and society. Therefore, with the help of psychology and related corporate employee mental health tests and surveys, we can minimize the contradictions from all aspects of business management and streamline the work procedures. The implementation of mental health maintenance and quality improvement can help employees solve psychological problems, help enterprises to reduce management difficulty and improve the personal quality of employees. It is an effective way to strengthen enterprise management.

\subsubsection{Exploring the Model of Mental Health Maintenance and Quality Improvement in Driving School}

Through the centralized psychological assessment of 300 employees of the driving schools, we basically grasped the mental health status of the employees of the company. The main factors affecting the mental health and mood of employees are as follows: First, the company is downsizing, that is, reducing staff and increasing efficiency. Some employees show different psychological states, and there is sense of loss, crisis and anxiety. The second is the psychological problems caused by the safety training of trainees. A close look at the safety accidents that occurred in driving schools in recent years, most of which were caused by employees' violations. [4]There are reasons for the lack of strict management of enterprises, but more is caused by the low safety awareness and low safety quality of employees. It reflects the psychological pressure of employees and trainees who are afraid of accidents, fear of affecting the safety performance of enterprises, and fear of affecting the reputation of the company. The third is interpersonal relationship. Some people don't know how to get along with leaders and colleagues and handle various relationships, and can't balance the conflict between work and family. The fourth is work stress. Closed environment, no exercise at regular times, and the tension of professional competition all bring psychological pressure to employees. The fifth is a personal problem. 
Individuals have concerns and do not dare to regard mental health education as their normal needs. They believe that this is a privacy issue. They do not want the company to know, and some people have concerns about their safety and confidentiality.

For this reason, the mental health management model of the enterprise is proposed. Including: in the early stage, the establishment of a psychological assessment research group, the development of assessment plans, plans and promotion tables, the issuance of work notices to carry out propaganda promotion, and good information collection; in medium stage, on-site publicity ,group psychological test, mental health lecture, evaluation of employees' mental health status; in the late stage, the employee's psychological files, statistical analysis of the data were established, psychological health advice was proposed, individual consultations were carried out, and normal mental health management measures were implemented.

\subsection{Suggestions on Constructing Mental Health Management Mode of Driving School Enterprises}

\subsubsection{Overall Status}

At the national level, documents should be issued for the mental health of employees. At present, only the Ministry of Education has issued mental health documents focusing on college, middle and primary school students, and there are few documents on the mental health of employees.

\subsubsection{Fully Analyzing the Dynamics of Employee Thinking}

Establishing a detailed and accurate database of employee information is an important basis for mastering the dynamics of employees' thinking. The employee can first fill in the personal basic information, supplement and improve the situation through investigation and visit, and grasp the employee's information such as work experience, growth environment, family members, health conditions economic conditions and special interests as much as possible without infringing on personal privacy. With sincere attention and warm heart help as the starting point, it should truly reflects the company's people-oriented management philosophy. At present, in order to grasp the ideological dynamics of employees in time, some enterprises set up a special psychological evaluation team to formulate evaluation plans and promotion tables, and issue work notices to promote publicity, and cooperate with on-site publicity, group psychological tests, mental health lectures, employees' mental health status assessment, establishment of employee psychological files, summary data statistical analysis, then propose mental health advice, follow up with the concerned object to conduct individual consultation, implement normalized mental health maintenance and quality improvement measures.

In recent years, with the rapid development of society, people's life rhythm has accelerated rapidly, interpersonal relationships have become more complicated, work pressures have increased, and more and more people have psychological problems such as anxiety and depression. For enterprises, first of all, it is necessary to provide professional training of necessary psychological knowledge to managers at all levels so that they can lead employees to mental health with a healthy mentality, and promote mental health knowledge. According to relevant information from the health department, mental disorders rank first in China's disease rankings, surpassing diseases such as cardiovascular and cerebrovascular, respiratory and malignant tumors.

\subsubsection{Introduce the EAP Program to Strengthen Professional Mental Health Promotion and Counseling}

Evaluation of employee status through mental health assessment, lectures, training, individual counseling, team coaching, etc., mainly including psychological counseling experts, professional measurement tools (SCL-90, EPQ, MMPI), counseling room, database establishment, etc. In terms of aspects, professional psychologists are the key factors for the employee health assistance program to achieve good results. Professional measurement tools are mainly used to measure the psychological status of employees. The purpose is to find out the employees through the scientific assessment of the mental health status of employees. The root cause of psychological problems. The 
counseling room is a fixed place for companies to carry out various forms of psychological counseling, including consulting hotlines, online counseling and personal counseling. The database is mainly used to establish employee mental health files, and to track and record employees' psychological status. In addition, actively and effectively promote mental health knowledge, intervene in the psychological state of employees, provide some ways to eliminate negative emotional effects, prevent mental illness, and reduce employee psychological stress and job burnout. In addition, strengthen the training of supervisors, master the methods of psychological management, improve communication and conflict management skills, and timely, effective and scientific guidance when employees have psychological problems. At the same time, the training of skills and technology will be strengthened to improve the technical level of employees, improve self-confidence and reduce work pressure. Finally, we can use positive education as a breakthrough to carry out positive psychological education for all personnel, and enhance work motivation, self-confidence, dedication and work ability.

\subsubsection{Play the Role of the "Warm support" Project}

The final implementation of employee mental health education requires institutional guarantees, with special institutions, professional personnel and special investment to promote. Enterprise managers must earnestly perform their maintenance functions and protect the basic rights and interests of employees. At the same time, hire psychological counseling specialist and strengthen the staff's mental health education, and cultivate the internal strength and skills for responding to stress. Enterprises should create conditions to encourage employees to participate in professional psychological counseling training certification, or often organize professional mental health lectures, and can also introduce professionals with these conditions to enrich the enterprise. [5]

\subsubsection{Constantly Improve the System and Protect the Rights and Interests of Employees}

Expand the participation of employees in business management, including the participation of corporate decision-making, the establishment of corporate systems, and let employees have a sense of ownership. Establish an employee complaints system, set up a suggestion box or an online forum, adopt the reasonable demands of employees, and give employees a space to release their mood. Improving the treatment of front-line employees will help to improve employees' sense of identity with their profession, so that employees can be mentally and materially satisfied, thereby improving their social status. Implement the labor security system, arrange employees' rest and reunite with their families reasonably. If conditions permit, we can also arrange employee recuperation, etc., which can effectively relieve employees' mental stress.

\section{Conclusion}

Paying attention to mental health is something that cannot be underestimated in the HSE management system. In addition to regular items for employee medical examinations, it is necessary to add mental health checks and tests. On the basis of psychological assessment, according to the different characteristics of employees, the mental health management model is integrated into HSE management, and necessary and appropriate interventions are made in a timely and effective manner to adjust the psychological state of employees to an ideal level. So that it can effectively prevent potential safety hazards due to psychological problems, and provide guarantee for the smooth and efficient implementation of HSE management objectives, and also creates conditions for the harmonious development of enterprises and the improvement of efficiency.

\section{Acknowledgements}

In this paper, the research was sponsored by Horizontal topic-Mental Health Maintenance and Quality Improvement of Driving School Staff (Enterprise: Gongzhuling City Zhengda Driver Training School) 


\section{References}

[1] Dawei Liao, Xiaomin Ren, Xiaoxin Dong, et al. Analysis of psychological assessment results of petrochemical pipeline storage and transportation staff [J]. Safety, Health and Environment, 2012, 12(1):27-30

[2] Fuying Cai, Bin Li.Summary and Analysis of Research on Employee Assistance Program [J]. Value Engineering, 2008(2):141

[3] Wei Shen, Long Chen. Investigation on of employees in state-owned enterprises [J].Chinese Journal of Behavioral Medical Sciences, 2004(6)

[4] Juan Li. Analysis and Countermeasures of Mental Health of Enterprise Employees [J]. Safety, Health and Environment, 2011, 11(7):49-50

[5] Hua Li. Analysis the stress status of Mental Health of Enterprise Employees [J]. Health Environment, 2013, 12(3):88 